EUROPEAN HONORS COUNCIL

Note

\title{
Good practice: Writing a book
}

Anton Peeters and Fred Wiegant

Honors program Biology, Utrecht University, The Netherlands; A.J.M.Peeters@uu.nl and F.A.C.Wiegant@uu.nl

Correspondence: A.J.M.Peeters@uu.nl

Received: 16 August 2018; Accepted: 12 December 2018; Published: 7 January 2019

Keywords: Honors biology, complex project, book writing, collaborating, student-driven

Note to reader: honors keywords (see introductory article of this issue) in italics in the text

\section{Introduction}

In order to stimulate 21 st century skills, including communication and cooperation competencies, honors students are challenged to write a (popular science) book or to make an extensive website on a biologically relevant subject during one academic year. This is done, in partly extra-curricular fashion, within the two-year honors program at the Department of Biology of Utrecht University, The Netherlands. Honors students then work as a team where they have a lot of freedom in the choice of the main subject, chapter topics, working methods, and planning. The book is usually published by a commercial publisher and used in the first academic year of the regular program. The honors program is offered in addition to the second and third academic year of the regular bachelor curriculum. This good practice is programmed during the first year of the honors program (the second bachelor year).

\section{Why this good practice?}

The regular program has a clear structure in the first academic year with relatively little room for the students to follow their own interests. In the second year of study, it is clearer what their interests may be, and students who participate in the honors program can explore their interests in the context of a complex project. They have to work together on an open-ended project where they really depend upon each other. This usually results in a book that is published commercially. The project offers them the possibility of discovering talents and possibilities for further academic development, but it is also a challenge for them to build a community because all students participate in the same project. It gives them the opportunity to discover and further develop their talents, such as critical thinking, collaboration, leadership, creativity, and giving and receiving feedback. 


\section{Target group and target group size}

The honors program has been designed for second- and third-year students of the regular $\mathrm{BSc}$ program in Biology who are willing and able to do more than the regular program requires. At the end of their first year, they can sign up for this honors program and are selected on the basis of their motivation, grades, and an interview. Usually, between 12 and 20 motivated and talented biology students are selected to participate in the program. Student activities take place in extra-curricular fashion during the academic year that they are working on this intensive honors group project. They invest between 200-400 study hours, which is equivalent to 7.5 - $15 \mathrm{ECs}$.

\section{Educational design (structure)}

The honors program starts with a meeting where the teacher introduces the (very open) assignment and where a number of suggestions for possible topics are given.

In a number of subsequent meetings the students:

- decide upon a topic in which all participants can contribute a subtopic based on their interests.

- ensure that there is no overlap in subtopics.

- determine the shape of the end product (book, website).

- determine the target group of the product: mostly last year high school students and firstyear (freshmen) biology students.

Since this is a complex process with many different tasks, the students make a division of tasks into subgroups which usually looks as follows:

- Two editors-in-chief: they manage the entire process, determine the deadlines, and pay attention to the overall quality and coherence of the book. If there are more than two volunteers for being editor-in-chief, the group will select two of them based on a pitch by these volunteers in which they emphasize their experience and vision.

- An editorial team: they make a time schedule, set deadlines, and supervise the quality and consistency of the book chapters by organizing peer and expert feedback and monitoring the synergy between chapters.

- Illustrators: they are responsible for all illustrations and graphics, including the cover.

- Symposium committee: organization of the book presentation.

- Committees that are responsible for finances, PR, communication with the publisher, etc. (everything they deem necessary).

Then, they start writing chapters (alone or in pairs), monthly progress meetings are organized where the teachers are present, there are interim meetings of the various committees, peer feedback is organized, and experts are consulted who also give feedback on the written chapters, etc.

The teachers do not provide any pedagogical or subject-specific guidance during the further process (only in case of emergency) but do have regular consultations with the editors-inchief about the process. In addition, they provide students with 'just-in-time' workshops or modules, for example, about academic writing, cooperation, critical and creative thinking, and ethics.

The teachers have a facilitating role as coach of the honors community. In the beginning, no 
indication is given about the process and what the product should be. The teachers are critical and involved but do not take part in making the decisions.

The group project is an essential part of the honors program. The task is so complex that students have to work together intensively, divide tasks, and make joint decisions to achieve the desired result. They have to be able to rely on each other during the project.

The program starts in September, lasts throughout the academic year, and ends in May or June (Wiegant, Boonstra, Peeters \& Scager, 2012). The process of writing a popular scientific book, and getting it published increases their sense of doing something relevant. In terms of reward, students emphasized that the intrinsic value of the end product such as a book, but also an article or research proposal, encourages them to complete the task. As one student of this course put it: 'We also had other project groups, but that was taken less seriously, that result would not go beyond the classroom, while in this project that is the case.' In this complex task of writing a book, a variety of different '21st century skills' were included: intensive collaboration, clear communication, organizing effective meetings, developing leadership skills, and developing creative, innovative, reflective, and critical thinking skills. In their next honors year, the students design and provide a piece of education for first-year students about the content of their project. In these sessions, firstyear students also read and discuss one or more chapters of the book.

\section{Student assessment}

A final grade is provided to each individual student, which is based on the assessment by the teachers, by their peers, and by themselves. Both teachers assess the following aspects: presentation of their chapter to the group, quality of the written chapter, quality of the overall group process, and quality of the end product. Peer assessment by fellow students is based on the degree to which individual students participate in the group process as well as in committee activities in relation to their critical, creative, and collaborative input and skills. Finally, a written self-assessment is sent to the teachers, which includes a grade the students would give themselves for the project substantiated with arguments. Incidentally, it is striking that the students find the final product more important than a grade (Scager, Boonstra, Peeters, Vulperhorst \& Wiegant, 2016).

\section{Experiences}

Some excerpts from interviews with honors students give an impression of their experiences.

An honors student wrote this about his passion for this project: 'Outsiders thought that publishing a book would not work, but it did and that is very motivating.'

Furthermore, the participants have also received a 'sense of community,' the feeling of belonging to this group, and, in fact, the feeling that this group was their community. So, there was ownership. Statements by students about this include: 'Yes, togetherness' and 'For some, it was stimulating to get to know each other well. Silent people too become involved.'

Another feature of this community is that it gradually develops into a culture of excellence. Students feel challenged to get the best out of themselves, to achieve something that really 
matters, and they do stimulate each other. Honors students have written the following about the culture of excellence: 'You know that you have been selected and that feels special' and 'There is a different atmosphere than in the regular program: stimulating.'

In every community, a pattern of interactions has been formed through joint projects, working groups for program or product development, partly formal and partly informal. Contact via social media and other ICT applications plays an important role in this.

Honors students have said about the internal organization of their community: 'The editors were important, but there were also committees for finance, PR and illustrations. Everyone was active in one or two committees. There was also an editor in every committee' and 'There was also a layout committee with us. Every chapter was worked in pairs.'

Honors students reported about the function of the community: 'I started reading more scientific literature, I became more interested in that. I have also developed my presentation skills more by the honors program and the community. The book project has also encouraged me to write more' and 'Through the community you can achieve more things that are otherwise unachievable.'

-About the role of the teacher

Students report in a majority (68\%) that their coach encouraged the development of their skills ( $10 \%$ said 'very strong', $14 \%$ 'a bit' and $7 \%$ did not). A student explains this: 'We were given the assignment to create something like a group project. We decided to write a book. The teachers gave us the opportunity and provided the right conditions, but we had to arrange the process ourselves.' A teacher adds: 'In the honors program, we have a group of students making a book together. It is important that they are responsible for the whole process, from the first brainstorm session to the final publication. They are creative, they work together and are critical of themselves, each other and the product. Students are the owners of their own learning in this set-up: that works better than someone else prescribing what and how they should learn. The learning pleasure is many times greater' (Peeters, 2014).

-About the results:

In a poll among students about the extent to which they acquired 21st century skills, they found that they had learned more about teamwork and communication but also skills related to personal leadership and their ability to solve problem to some extent.

The series of books and one website which have been produced over the past eight years is shown in Figure 1.

\section{Time requirement for teachers}

Teachers have a role on the sideline. They are at the monthly (evening) meetings in which the various committees of students report their progress to each other, joint decisions are taken, and the editors discuss the progress, stumbling blocks, and deadlines in the overall process. Here, the teachers can, if necessary, ask critical questions about the progress of the process or the decisions the group make. In addition, teachers may provide 'just-in-time' workshops, such as on cooperation, creativity, and academic writing skills. 
Figure 1. The covers of the popular science books as well as a website that have been produced by honors students at the Department of Biology, Utrecht University, over the past 8 years. Most books are available at Uitgeverij de Graaff in Utrecht, The Netherlands.
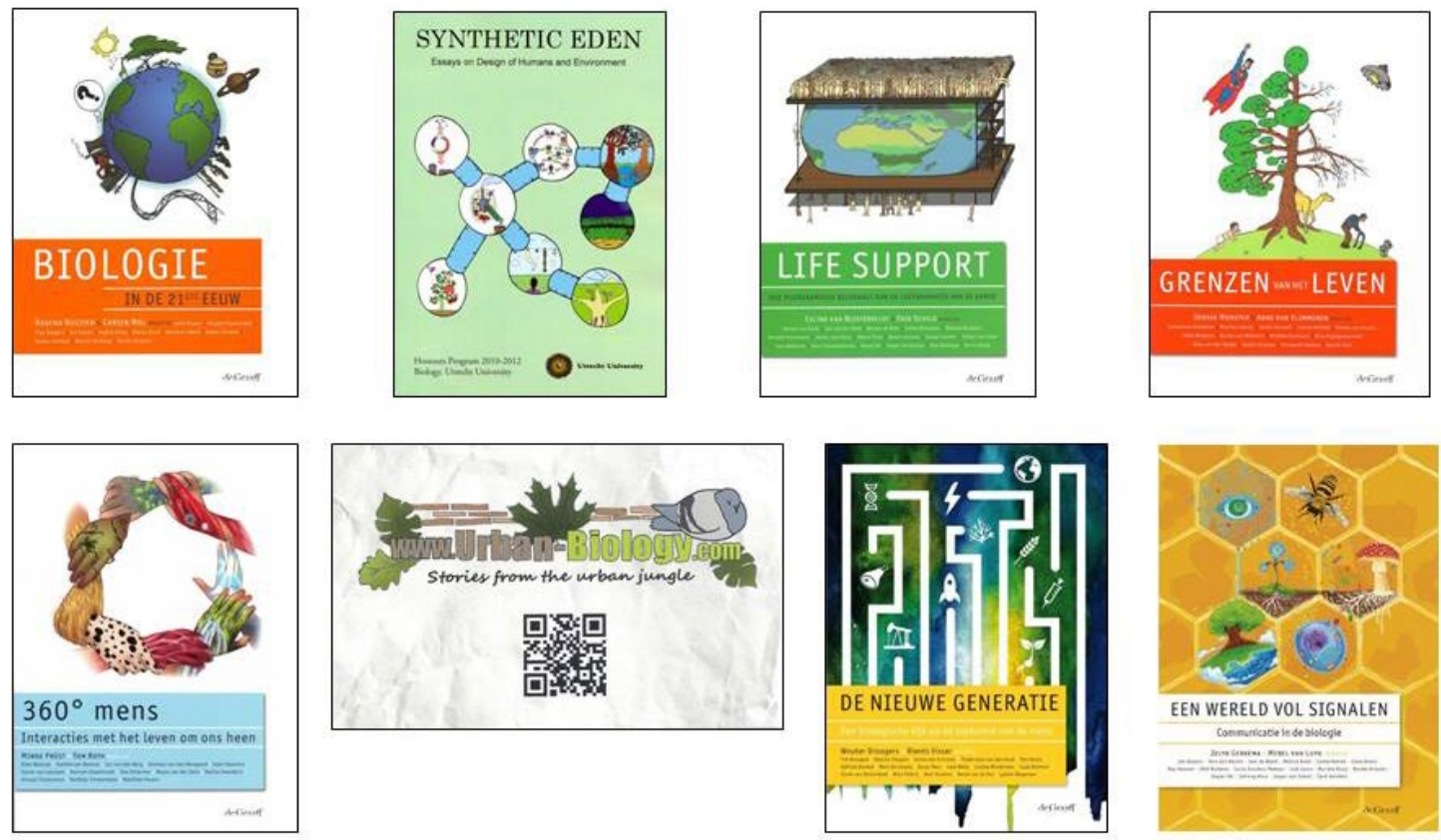

\section{Tips for teachers}

It is important that it is a student-driven process. Students must feel that they are the owners of this project. They are thrown into the deep, and they will, especially in the beginning, wonder how they have to solve specific problems they encounter as a group or within a committee. Because the teachers keep quiet at those moments that these problems are discussed in group meetings, they quickly feel that it is really up to them to take the helm.

Usually a document is provided that was once drafted by a previous editor-in-chief with tips for a next group of students. However, practice shows that each group comes to an end product in different ways.

\section{Tips for students}

The confusion that arises in the first instance among the students frustrates them because they are not used to that in regular education. It is precisely the lack of structure and not knowing what they have to 'meet' that will make them aim very high. They themselves create a structure that suits them and ensures that every student in the program fulfils his or her tasks. In the end, everyone feels that they have been heard and respected.

\section{Transfer to other programs}

Many students think that some honors activities are suitable for inclusion in a regular program. A number of adjustments are mentioned as desirable, such as shortening, organizing group projects around well-executable projects, more workshops, a stricter timetable, more guidance, giving real credits, not making it a compulsory but optional course, and reduce the level. A student had the opinion that the honors activities do not fit 
in with the regular program because the honors program is specially designed for students who want to get more out of their studies.

\section{References, additional information, and relation with Circle of Talent Development}

\section{$\underline{\text { References }}$}

Peeters, T. (2014). Teaching fellow Ton Peeters prepares students for unpredictable labor market (interview in Dutch). DUB (Digital University Journal Utrecht University) 24 October 2014. https://www.dub.uu. $\mathrm{nl} / \mathrm{nl} /$ achtergrond/teaching-fellow-ton-peeters-bereidtstudenten-voor-op-onvoorspelbare-arbeidsmarkt

Scager, K. Boonstra, J., Peeters, T., Vulperhorst, J. \& Wiegant, F. (2016) Collaborative Learning in Higher Education: Evoking Positive Interdependence. CBE Life Science Education, 15: ar69. https://www.ncbi.nIm.nih.gov/pmc/articles/PMC5132366/

Wiegant, F., Boonstra, J., Peeters, A. \& Scager, K. (2012). Team-based learning in honors science education: the benefit of complex writing assignments. J National Collegiate Honors Council 13, 219-227. http://digitalcommons.unl.edu/nchcjournal/364/

\section{Additional information}

Link to the honors program biology:

https://www.uu.nl/bachelors/biologie/honoursonderwijs

\section{$\underline{\text { Relation with Circle of Talent Development }}$}

In the introductory article of this issue of JEHC, the 'Circle of Talent Development' has been described. Based on interviews with forty honors students and literature about honors programs, it reflects relevant activities of students regarding the development of their talents in an honors program. The author of this note has been asked to score the good practice in relation to the activities in the Circle of Talent Development. The meaning of the scores is: + = somewhat important; ++ = moderately important; +++ = very important; - = not applicable or irrelevant. The scores are intended to illustrate the strengths of a good practice for the reader. 
Figure 1. Circle of Talent Development in relation with the good practice 'Writing a book' with the teacher's scores

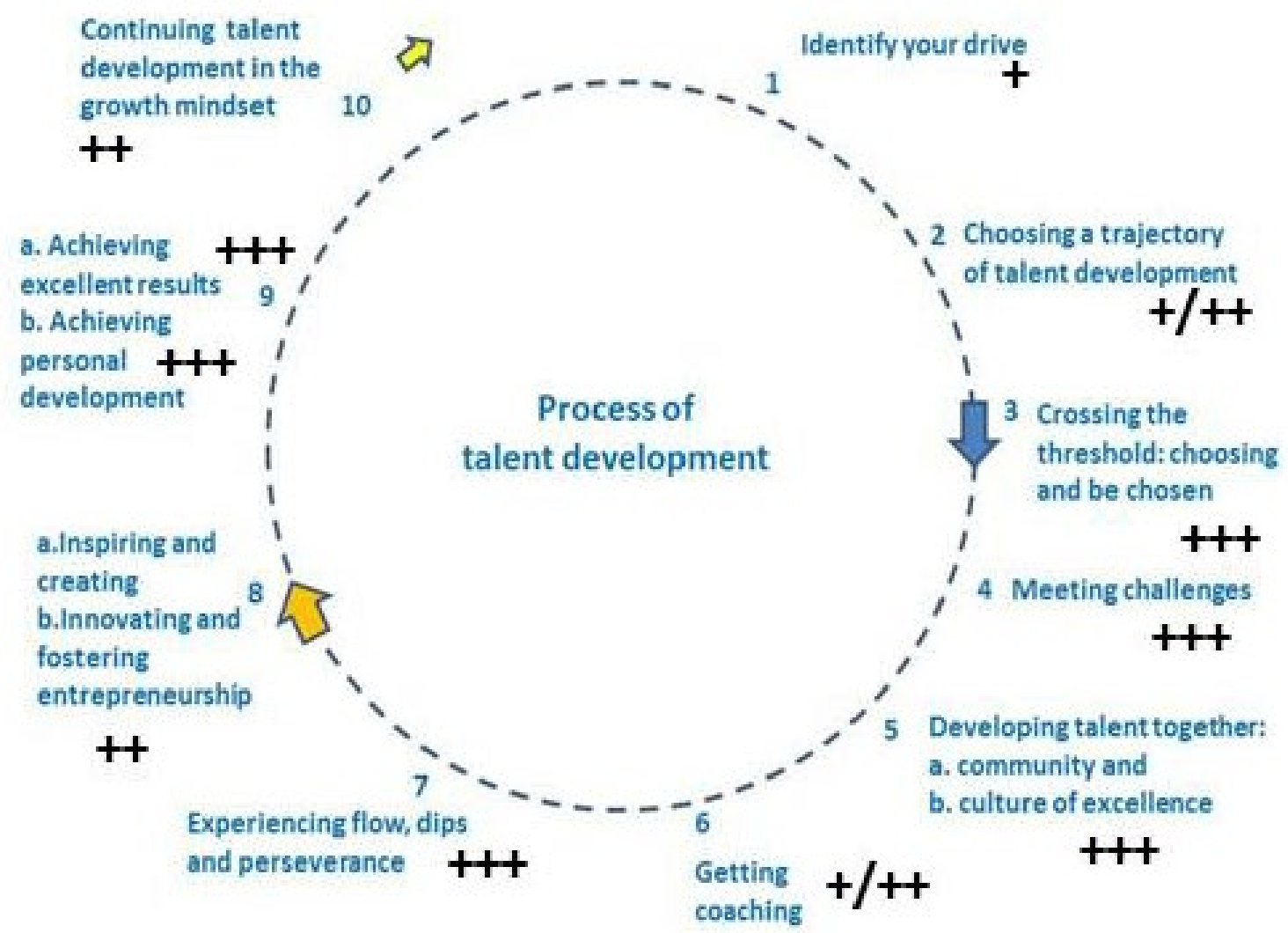

Question to the teacher: What makes this good practice attractive for other teachers? The teacher of this practice argues: 'It is wonderful to see students become more mature, develop their competencies, and become a real team. This is an opportunity for being proud of what your students will achieve.' 